\title{
IT auditing quality assessment based on human, technical and contextual factors.
}

\author{
Daisy Imbaquingo_Esparza ${ }^{1,2}$, Lorena San Pedro ${ }^{1}$ Javier Díaz $^{2}$, Tatyana Satos_Echeverría ${ }^{1}$, Silvia Arciniega ${ }^{1}$ and \\ MacArthur Ortega 1,2
}

$\begin{array}{ll}1 & \text { Universidad Nacional de la Plata; } \underline{\text { daisy.imbaquingoe@info.unlp.edu.ar }} \underline{\text { cosme.ortegab@info.unlp.edu.ar }} \\ 2 & \text { Universidad Técnica del Norte; } \underline{\text { mlsanpedror@utn.edu.ec }} \underline{\underline{\text { rarciniega@utn.edu.ec }}} \underline{\text { tksaltos@utn.edu.ec }} \\ \text { * Correspondence: } \underline{\text { daisy.imbaquingoe@info.unlp.edu.ar }} ; \text {; Tel.: (593 979279791) }\end{array}$

\begin{abstract}
IT auditing quality has been defined by results obtained in the process. Meanwhile, multiple studies have been done to enhance it therefore, it continues to be a topic interest and research so it is worth mentioning that its quality relies on trained competent auditors and experts able to develop a process correctly, adapting to clients and to manage auditing inherent risks According to results from the IT audit, low quality and security levels have been identified in terms of the human, technical and contextual factors, affecting audit quality. The objective of this investigation is to identify metrics and to determine their own corresponding factor applying an exploratory type of research. In order to achieve such aim, a targeted survey was designed and implemented at the Institute of Internal Auditors of Ecuador since they have the knowledge and expertise in the field. A factor analysis statistics technique was applied to data gathered to verify that it relates to the identified factors as dimensions are reduced, thus the most impacting metrics may assess the quality of IT audits. Analysis results yielded a mean score for each one of the assessed metrics, concluding that the technical factor is the most significative since it relates roles and task performance during the auditing process as well as control procedures. Finally, most auditing quality-related issues are mainly the outcome of an inferior management auditing process, therefore it is crucial that collegiate groups and professionals in the field validate the auditing process.
\end{abstract}

Keywords: Quality; factor analysis; metric system

\section{Introduction}

Auditing quality is not an easy concept to define, and to date there is no concept universally recognized. However, it is linked to applicable standards to be audited [2][6]. Similarly, quality perception depends on the discretion of the team who are involved in the process. [7].

The most acceptable concept is the extent of success of the processes performed [8] and to avoid subjective quality in auditing results, the preferred methodology's inherent risk should be considered [9].

Furthermore, auditing quality is defined based on the results yielded and despite several efforts to be enhance, it continues to be a subject worthy of attention and research [10]. Quality comes from qualified, motivated auditors in the correct design process adapting to the client so that inherent auditing risks are properly managed.

The first formal event to develop an auditing quality framework was performed by the Financial Reporting Council (FRC) in the UK in 2006. [11] Five auditing-quality drivers were identified: (1) An auditing firm's culture; (2) auditing partners and staff personal skills and qualities; (3) auditing effectiveness process; (4) reliability and auditing reports usefulness and (5) factors out of the auditors' hands affecting the auditing quality.

For and auditing process to be developed satisfactorily, it should be organized considering certain elements such as company size and its operations, the use of technology, 
resource availability and choice of auditing team and its competence. The auditing organization is considered as the responsible unit within a company in charge of auditing planning and proper fulfillment of the organizational objectives in regard to established standards. [8].

In this article, the concept of IT auditing quality is defined as the verification and validation process of results yielded from the monitoring exercise applied to analyze whether auditing products have pertinent criteria, opportunity and sufficiency, in addition to either adding value to the business or providing verified, independent objective information for the decision-making phase in the processing-related areas of the audited object.

Auditing quality results vary according to project conditions, meaning type of industry, audited company size, complexity of involved systems among others. [12], the quality revolves around key elements which altogether increase the likelihood of auditing enhanced efficiency and consistency [13]. Moreover, factors related to human, technical and contextual factors affecting the auditing quality are identified.

It is understood that a higher quality Audit is related to brand or specialized auditors in the industry, [11], [14], [15] claim that an auditor's experience, skills and specialized knowledge in the industry are positively related to audits quality. Outlined skills include communication and partnership, domain and process knowledge, professional development, personality traits as well as technical and auditing expertise and so on. Auditors should update clients data to provide effective auditing based on more detailed and relevant audit-testing [16].

Professional competence affects auditing quality, as auditors should have the expertise to interview, read quickly, understand statistics and computer use among other skills. On the other hand, accountability demonstrates that the auditor could have a satisfactory auditing performance, convinced that his work is carefully examined and verified by his supervisor who in turn is responsible to his employer. Thus accountability is decisive for the auditor since it affects the quality of the auditing process. [17].

In an study conducted by [18], the quality of the auditing was supported by two factors directly related to its performance. First, auditor's skills-expertise, knowledge, adaptability and technical efficiency--. Second, professionalism-able to work independently, objectivity, professional care, conflict of interest and judgement-.

The auditing environment is an additional quality- influencing factor, directly or indirectly [4], since it may have significative interactive effects in the auditing entry process. It has been discovered that many contextual characteristics influence the auditing quality such as auditor- partner fee, non-auditing additional fees and auditor continuity [11].

As the auditing results quality is influenced by several factors on premises, the lowquality and security issues are evident by the results from an IT auditing. Due to this fact, organizations are unlikely to obtain optimum results from decision-making processes aimed to enhance auditing processes.

The objective of this research work: i) To identify influencing quality results factors in IT auditing processes, ii) To understand group metrics in each factor.

To achieve these objectives, the study raises the following research questions:

1. What is the impact of influencing factors affecting the IT auditing process quality?

2. Which selected metrics for each factor influence auditing quality results?

\section{Materials and Methods}

The purpose of this research is to identify and define selected metrics so as to realize the emphasis of factors and its resulting metrics in auditing processes pursuing a greater approach in critical points within activities performed and results.

Since the study focuses on IT Auditing, the proposed approach was considered by [1] those analyzing a group of metrics affecting IT auditing processes quality. Next, it was supplemented with an exploratory investigation identifying potential factors and auditing quality-related metrics. After that, a targeted survey was designed and implemented 
on Internal Auditors of Ecuador who have the expertise to answer the survey. Then, A factorial analysis statistic technique was applied to the results gathered from the survey to verify that results are related to established factors in the bibliographical review, thus a dimension reduction occurs so that more impactful metrics assessing the quality of IT auditing results are obtained.

Potential metrics results are shown in Appendix A for a statistical analysis that determines whether they are grouped correctly allowing a dimension reduction based on its result.

A set of 94 metrics was validated by a group of academic experts in the auditing, IT auditing and engineering field to determine if the instrument is clear, precise and has a pertinent measuring scale and whether potential metrics are capable of achieving the objective in this study. Those surveyed responded on the basis of the seven-point Likert scale set from a totally low-to-totally high score to the following question What is each metric's extent of the impact on the quality of results from IT processes?

Next, an online survey was conducted and applied to Internal Auditors of Ecuador Institute specifically in the IT auditing and Information area. With a total of 475 registered answers the requirements are met so that a factorial analysis is developed, being considering that the minimum number of responses should be 100 [19]-[21], response rate to the number of metrics, considering 5:1 approach (5 responses per variable). software SPSS was used for the statistical analysis.

After that, a factorial analysis was performed to understand the relationship among metrics used in the survey so that a group of factors evidence most variability.

An internal consistency test through an Alfa de Cronbach was done, a reliability analysis to assess the metric-total correlation; scale reagents squared correlation and the reliability value if the reagent is eliminated. In this analysis, no reagent was eliminated since they have the same relation to the scale. All metrics keep the Alfa value =0,997 for the 94 selected metrics (see table 1). As a general rule, one Alpha equal to 0.7 or higher represents a consistent set of variables.

Table 1. Reliability analysis- SPSS obtained results

\begin{tabular}{cc}
\hline \multicolumn{2}{c}{ Reliability Statistics } \\
\hline Cronbach Alfa & $\mathbf{N}^{\circ}$ of elements \\
0,997 & 94 \\
\hline
\end{tabular}

Once the survey data consistency is checked, tests such as the Bartlett sphericity test were done to verify the significance of extracting factors from the set of metrics, which denotes that analyzed variables do not share a common variance. the Kaiser-Meyer-Olkin statistic (KMO) shows how much variance is present. For a factorization to be considered KMO index, values should be between ,70 - 79 and satisfactory when its value is higher than 0,80 in which case a factorization is feasible providing key factors valuable data, by the degree in which each metric is predictable from others. [19].

Table 2 shows sphericity tests and $\mathrm{KMO}$, where it is observed that the variable intercorrelation degree is strong confirming by the significance associated to the Bartlett sphericity test, that is 0,00 1. Similarly, KMO is 0,945 a value higher than 0,80 , so according to this indicator, the data matrix is suitable to perform factorization.

Table 2. Bartlett sphericity test and KMO SPSS results

\begin{tabular}{lll}
\hline \multicolumn{3}{c}{ KMO and Bartlett tests } \\
\hline \multicolumn{3}{c}{ Kaiser-Meyer-Olkin Sampling Adequacy } \\
Bartlett & Measurement & 0,945 \\
sphericity & gl $^{1}$ & 97784,441 \\
test & Sig. ${ }^{2}$ & 4371 \\
\hline
\end{tabular}

${ }^{1}$ Degree of freedom to obtain the observed significative value 
${ }^{2}$ Significance among variables

\section{Results}

Results include analyses for each metric from the survey to identify the ones affecting the quality of IT auditing and to observe how these metrics group into factors.

A score analysis was performed provided by those surveyed to verify the importance of each metric in the results phase, determining that metrics measurements vary from totally low, to totally high. As per consistency and approach [1], [22], in their research they focused on ten superior and inferior metrics considering an average score throughout the entire sample.

Table 3 shows the 10 highest scored metrics. Each element in the list is crucial when assessing the quality of auditing results since they hold a higher mean than 5.82 , meaning that most of them had an IT auditing quality impact rating from medium to totally high.

Table 3 . The ten best IT auditing quality rated metrics

\begin{tabular}{|c|c|c|}
\hline $\mathbf{N}^{\circ}$ & Survey Item & $\begin{array}{l}\text { Overall average } \\
\text { score }\end{array}$ \\
\hline M45 & $\begin{array}{l}\text { Auditing results are totally supported by documents and } \\
\text { evidence gathered in the auditing process }\end{array}$ & 5,97 \\
\hline M26 & The auditing team executes the audit impartially & 5,89 \\
\hline M18 & The auditor respects client's data confidentiality & 5,89 \\
\hline M47 & $\begin{array}{l}\text { Auditing team achieves stated objectives in the auditing } \\
\text { plan }\end{array}$ & 5,89 \\
\hline M25 & The auditing team demonstrates objectivity and integrity & 5,87 \\
\hline M5 & $\begin{array}{l}\text { Members of the auditing team work on the auditing ethi- } \\
\text { cally and with transparency }\end{array}$ & 5,86 \\
\hline M59 & Audit report results are clear and concise & 5,86 \\
\hline M87 & $\begin{array}{l}\text { Auditing team has the required permits to develop an au- } \\
\text { diting proces }\end{array}$ & 5,86 \\
\hline M93 & Auditing team is well informed regarding internal controls & 5,85 \\
\hline M61 & $\begin{array}{l}\text { Report presentation performed under IT auditing stand- } \\
\text { ards, manuals, guidelines and practices. }\end{array}$ & 5,83 \\
\hline
\end{tabular}

In general, the best rated metrics focus on the auditor's objectivity, ethics, transparency, audit's objectives achievement and how results are presented compared to [1], those who found planning and fieldwork as the best rated metrics. This fact indicates similarity between IT auditing identified metrics and TI standards since they require a greater planning approach considering objectives set and achieved.

Table 4 presents the 10 lowest metrics mean, resulting in less than 5.49 then the auditing quality results impact is rated as average or totally low, still being somehow relevant. However, in comparison with higher rated metrics, these become insignificant. Lower rated elements suggest that the organizational structure from the audited institution and the auditor skepticism are unimportant regarding IT auditing, in line with what has been stated by [1] in the last item.

Table 4. Ten IT auditing lowest -quality rated metrics

\begin{tabular}{clc}
\hline $\mathbf{N}^{\circ}$ & \multicolumn{1}{c}{ Survey Item } & $\begin{array}{c}\text { Overall } \\
\text { average }\end{array}$ \\
\hline M51 & $\begin{array}{l}\text { Client understands the purpose and process of IT auditing } \\
\text { M48 }\end{array}$ & $\begin{array}{l}\text { Findings, conclusions and recommendations were positively } \\
\text { perceived by the client }\end{array}$ \\
M41 & Auditing team uses documenting templates and forms & 5,48 \\
\hline
\end{tabular}


M30

Auditor has national and international certifications from auditing and IT auditing field

Auditing team has the client approval regarding tasks devel-

M10 oped

Auditor link-up to experts for support in the auditing pro-

M38 cess for results and client recommendations

Auditing team ensures the client takes part in the auditing

M9 process

Auditor has soft-skills - personal characteristics and compe-

M15 tences that show the way he gets along with others

The institution organizational structure reflected on the auditing plan

M31 Auditor is skeptic during the auditing process.

Similarly, a main component with varimax rotation analysis is carried out in order to perform a factorial varimax, simplifying factor interpretation. Factors having higher than 1 value are taken into account, while metric-factors have a larger than 0.6 cut since values are consistent with auditing-quality research done by [22] and [1]. Likewise, the orthogonally rotated factorial solution typify the existence of 5 latent factors and the contribution of each metric to the factor. As a whole, factors explain $84,754 \%$ variability in the original data as shown in table 5.

Table 5. Factorial analysis and item loads. Cells in bold represent the metric maximum while italics cells have a value lower than 0,6 therefore eliminated from the factorial analysis. Results obtained from SPSS

\begin{tabular}{|c|c|c|c|c|c|}
\hline \multirow{2}{*}{ Métric } & \multicolumn{5}{|c|}{ Factor } \\
\hline & 1 & 2 & 3 & 4 & 5 \\
\hline M1 & 0,448 & 0,295 & 0,416 & 0,522 & 0,266 \\
\hline M2 & 0,362 & 0,349 & 0,486 & 0,378 & 0,362 \\
\hline M3 & 0,453 & 0,355 & 0,157 & 0,511 & 0,111 \\
\hline M4 & 0,502 & 0,454 & 0,284 & 0,571 & 0,022 \\
\hline M5 & 0,465 & 0,468 & 0,266 & 0,512 & 0,061 \\
\hline M6 & 0,441 & 0,376 & 0,376 & 0,565 & 0,147 \\
\hline M7 & 0,445 & 0,386 & 0,338 & 0,472 & 0,184 \\
\hline M8 & 0,448 & 0,430 & 0,424 & 0,513 & 0,154 \\
\hline M9 & 0,253 & 0,695 & 0,417 & 0,418 & 0,328 \\
\hline M10 & 0,267 & 0,612 & 0,333 & 0,346 & 0,378 \\
\hline M11 & 0,334 & 0,642 & 0,507 & 0,374 & 0,178 \\
\hline M12 & 0,399 & 0,692 & 0,367 & 0,454 & 0,106 \\
\hline M13 & 0,370 & 0,481 & 0,407 & 0,522 & 0,062 \\
\hline M14 & 0,393 & 0,546 & 0,408 & 0,474 & 0,025 \\
\hline M15 & 0,364 & 0,610 & 0,451 & 0,311 & 0,160 \\
\hline M16 & 0,417 & 0,677 & 0,346 & 0,340 & 0,174 \\
\hline M17 & 0,462 & 0,651 & 0,341 & 0,369 & 0,051 \\
\hline M18 & 0,432 & 0,582 & 0,330 & 0,492 & $-0,013$ \\
\hline M19 & 0,418 & 0,685 & 0,348 & 0,324 & 0,098 \\
\hline M20 & 0,395 & 0,696 & 0,436 & 0,309 & 0,230 \\
\hline M21 & 0,363 & 0,613 & 0,362 & 0,486 & 0,102 \\
\hline M22 & 0,389 & 0,626 & 0,397 & 0,329 & 0,109 \\
\hline M23 & 0,347 & 0,486 & 0,481 & 0,343 & 0,204 \\
\hline M24 & 0,407 & 0,668 & 0,386 & 0,436 & 0,123 \\
\hline M25 & 0,425 & 0,492 & 0,412 & 0,557 & 0,060 \\
\hline M26 & 0,456 & 0,445 & 0,406 & 0,578 & 0,004 \\
\hline
\end{tabular}




\begin{tabular}{|c|c|c|c|c|c|}
\hline M27 & 0,399 & 0,626 & 0,396 & 0,418 & 0,115 \\
\hline M28 & 0,438 & 0,602 & 0,330 & 0,399 & 0,040 \\
\hline M29 & 0,433 & 0,612 & 0,343 & 0,436 & 0,032 \\
\hline M30 & 0,383 & 0,611 & 0,327 & 0,302 & 0,327 \\
\hline M31 & 0,326 & 0,543 & 0,225 & 0,014 & 0,262 \\
\hline M32 & 0,427 & 0,526 & 0,272 & 0,247 & $-0,086$ \\
\hline M33 & 0,360 & 0,759 & 0,294 & 0,290 & 0,040 \\
\hline M34 & 0,438 & 0,731 & 0,239 & 0,328 & $-0,062$ \\
\hline M35 & 0,392 & 0,721 & 0,324 & 0,248 & 0,114 \\
\hline M36 & 0,481 & 0,673 & 0,282 & 0,311 & $-0,030$ \\
\hline M37 & 0,386 & 0,540 & 0,360 & 0,150 & 0,148 \\
\hline M38 & 0,342 & 0,746 & 0,294 & 0,218 & 0,107 \\
\hline M39 & 0,461 & 0,704 & 0,295 & 0,274 & $-0,101$ \\
\hline M40 & 0,424 & 0,713 & 0,283 & 0,368 & 0,005 \\
\hline M41 & 0,632 & 0,436 & 0,213 & 0,362 & 0,145 \\
\hline M42 & 0,528 & 0,431 & 0,268 & 0,434 & 0,047 \\
\hline M43 & 0,704 & 0,420 & 0,207 & 0,295 & 0,132 \\
\hline M44 & 0,608 & 0,483 & 0,307 & 0,309 & 0,204 \\
\hline M45 & 0,634 & 0,428 & 0,285 & 0,446 & 0,074 \\
\hline M46 & 0,659 & 0,521 & 0,331 & 0,244 & 0,133 \\
\hline M47 & 0,571 & 0,428 & 0,320 & 0,391 & $-0,008$ \\
\hline M48 & 0,635 & 0,275 & 0,329 & 0,378 & 0,187 \\
\hline M49 & 0,741 & 0,341 & 0,319 & 0,307 & 0,092 \\
\hline M50 & 0,633 & 0,427 & 0,256 & 0,354 & 0,169 \\
\hline M51 & 0,646 & 0,317 & 0,334 & 0,148 & 0,364 \\
\hline M52 & 0,661 & 0,371 & 0,413 & 0,293 & 0,255 \\
\hline M53 & 0,691 & 0,425 & 0,322 & 0,318 & 0,087 \\
\hline M54 & 0,719 & 0,397 & 0,315 & 0,349 & 0,024 \\
\hline M55 & 0,702 & 0,387 & 0,318 & 0,280 & 0,214 \\
\hline M56 & 0,675 & 0,401 & 0,308 & 0,382 & 0,127 \\
\hline M57 & 0,654 & 0,423 & 0,414 & 0,132 & 0,276 \\
\hline M58 & 0,679 & 0,388 & 0,450 & 0,182 & 0,146 \\
\hline M59 & 0,720 & 0,361 & 0,355 & 0,296 & 0,117 \\
\hline M60 & 0,687 & 0,384 & 0,403 & 0,269 & 0,157 \\
\hline M61 & 0,507 & 0,364 & 0,354 & 0,358 & $-0,011$ \\
\hline M62 & 0,676 & 0,437 & 0,383 & 0,256 & 0,100 \\
\hline M63 & 0,677 & 0,428 & 0,389 & 0,242 & 0,186 \\
\hline M64 & 0,568 & 0,310 & 0,380 & 0,396 & 0,030 \\
\hline M65 & 0,721 & 0,331 & 0,403 & 0,272 & 0,141 \\
\hline M66 & 0,703 & 0,346 & 0,400 & 0,237 & 0,169 \\
\hline M67 & 0,665 & 0,334 & 0,444 & 0,231 & $-0,004$ \\
\hline M68 & 0,697 & 0,393 & 0,416 & 0,303 & 0,040 \\
\hline M69 & 0,666 & 0,369 & 0,303 & 0,349 & $-0,009$ \\
\hline M70 & 0,502 & 0,394 & 0,392 & 0,304 & $-0,061$ \\
\hline M71 & 0,696 & 0,362 & 0,422 & 0,327 & 0,078 \\
\hline M72 & 0,710 & 0,384 & 0,417 & 0,263 & 0,084 \\
\hline M73 & 0,702 & 0,403 & 0,445 & 0,224 & 0,040 \\
\hline M74 & 0,701 & 0,397 & 0,407 & 0,248 & 0,037 \\
\hline M75 & 0,692 & 0,382 & 0,408 & 0,202 & 0,208 \\
\hline M76 & 0,696 & 0,377 & 0,408 & 0,254 & $-0,030$ \\
\hline M77 & 0,688 & 0,399 & 0,432 & 0,266 & 0,038 \\
\hline M78 & 0,656 & 0,414 & 0,417 & 0,345 & 0,032 \\
\hline
\end{tabular}




\begin{tabular}{llllll} 
M79 & $\mathbf{0 , 6 9 8}$ & 0,329 & 0,458 & 0,280 & 0,018 \\
M80 & 0,387 & 0,275 & 0,582 & 0,114 & 0,115 \\
M81 & 0,455 & 0,324 & $\mathbf{0 , 6 2 5}$ & 0,298 & 0,084 \\
M82 & 0,423 & 0,367 & $\mathbf{0 , 6 9 8}$ & 0,189 & 0,093 \\
M83 & 0,446 & 0,328 & $\mathbf{0 , 6 8 3}$ & 0,247 & 0,208 \\
M84 & 0,425 & 0,377 & $\mathbf{0 , 6 7 0}$ & 0,214 & 0,266 \\
M85 & 0,507 & 0,399 & 0,591 & 0,307 & 0,104 \\
M86 & 0,475 & 0,413 & $\mathbf{0 , 6 3 8}$ & 0,253 & 0,032 \\
M87 & 0,513 & 0,355 & 0,599 & 0,294 & 0,030 \\
M88 & 0,461 & 0,319 & $\mathbf{0 , 6 2 4}$ & 0,272 & 0,108 \\
M89 & 0,517 & 0,375 & 0,528 & 0,376 & $-0,104$ \\
M90 & 0,451 & 0,340 & 0,519 & 0,370 & 0,022 \\
M91 & 0,510 & 0,382 & 0,596 & 0,335 & $-0,147$ \\
M92 & 0,459 & 0,414 & $\mathbf{0 , 6 6 7}$ & 0,251 & 0,057 \\
M93 & 0,408 & 0,351 & 0,505 & 0,389 & 0,024 \\
M94 & 0,507 & 0,352 & 0,594 & 0,372 & $-0,042$ \\
\hline
\end{tabular}

Metrics not meeting the analysis value such as lower to 0,6 are eliminated from the analysis while elements lacking of load value are: M1, M2, M3, M4, M5, M6, M7, M8, M13, M14, M18, M23, M25, M26, M31, M32, M37, M42, M47, M61, M64, M70, M80, M85, M87, M89, M90, M91, M93, M94.

Finally, the ultimate analysis instrument is comprised by 64 reagents that, reanalyzed are grouped into 3 factors matching the analyzed theory in [23]. Factors are solid representations of a previously studied theoretical component, consequently the factorial analysis should identify a set of reagents for abstract-concepts since factors matching theoretical basis means positive validity evidence [1], [20], [21], [24]. Identified factors are labeled as human, technical and contextual according to the theoretical basis. The final analysis solution converged in new iterations explaining $83.788 \%$ variance. Items reveal factorial loads higher than 0,6 within its own factor and communalities higher than 0,694 ordered from highest to lowest, grouped in 3 identified factors as shown in Table 6.

Table 6. Final solution factorial analysis and metric loads. Bold cells represent the maximum load while the factor belonging to the reagent. Results obtained from SPSS

\begin{tabular}{|c|c|c|c|}
\hline \multirow{3}{*}{ Métrica } & \multicolumn{3}{|c|}{ Factor } \\
\hline & 1 & 2 & 3 \\
\hline & Técnico & Humano & Contextual \\
\hline M49 & 0,789 & & \\
\hline M65 & 0,764 & & \\
\hline M59 & 0,758 & & \\
\hline M54 & 0,757 & & \\
\hline M72 & 0,757 & & \\
\hline M79 & 0,750 & & \\
\hline M66 & 0,749 & & \\
\hline M71 & 0,745 & & \\
\hline M55 & 0,742 & & \\
\hline M76 & 0,742 & & \\
\hline M43 & 0,739 & & \\
\hline M74 & 0,738 & & \\
\hline M73 & 0,736 & & \\
\hline M68 & 0,728 & & \\
\hline M53 & 0,725 & & \\
\hline M60 & 0,724 & & \\
\hline M56 & 0,720 & 0,512 & \\
\hline
\end{tabular}




\begin{tabular}{|c|c|c|c|}
\hline M69 & 0,719 & & \\
\hline M77 & 0,719 & & \\
\hline M75 & 0,718 & & \\
\hline M58 & 0,716 & & \\
\hline M67 & 0,714 & & \\
\hline M62 & 0,712 & & \\
\hline M63 & 0,703 & & \\
\hline M78 & 0,703 & & \\
\hline M52 & 0,697 & & \\
\hline M45 & 0,695 & 0,555 & \\
\hline M48 & 0,686 & & \\
\hline M41 & 0,681 & 0,528 & \\
\hline M46 & 0,679 & 0,554 & \\
\hline M51 & 0,677 & & \\
\hline M50 & 0,670 & 0,509 & \\
\hline M57 & 0,669 & & \\
\hline M44 & 0,638 & 0,554 & \\
\hline M40 & & 0,792 & \\
\hline M33 & & 0,791 & \\
\hline M38 & & 0,775 & \\
\hline M34 & & 0,774 & \\
\hline M39 & & 0,750 & \\
\hline M35 & & 0,748 & \\
\hline M19 & & 0,743 & \\
\hline M36 & 0,524 & 0,734 & \\
\hline M17 & 0,515 & 0,730 & \\
\hline M29 & & 0,716 & \\
\hline M12 & & 0,711 & \\
\hline M24 & & 0,702 & \\
\hline M10 & & 0,696 & \\
\hline M28 & & 0,692 & \\
\hline M21 & & 0,677 & \\
\hline M15 & & 0,672 & \\
\hline M30 & & 0,668 & \\
\hline M27 & & 0,656 & \\
\hline M20 & & 0,646 & \\
\hline M16 & & 0,644 & \\
\hline M22 & & 0,632 & \\
\hline M9 & & 0,628 & \\
\hline M11 & & 0,623 & 0,527 \\
\hline M83 & & & 0,715 \\
\hline M84 & & & 0,708 \\
\hline M82 & & & 0,677 \\
\hline M92 & 0,520 & & 0,656 \\
\hline M81 & 0,515 & & 0,634 \\
\hline M88 & 0,530 & & 0,622 \\
\hline M86 & 0,535 & & 0,606 \\
\hline
\end{tabular}

\section{Discussion}

Each auditing process is unique and success depends on the circumstance and factorselection. Additionally, its metrics should support development and practice of the process. [12], [13]. Likewise, auditing quality revolves around key factors identified in the 
research. It is summarized that this process should be designed by highly trained and motivated auditor sable to appreciate technical, contextual or environmental factors that adequately adjust to individual auditing conditions in each audit.

\section{Technical Factor}

Related to the auditing performance activities during the process including organization, strategy and planning, methodology selection, field work, results and reports, evidence based on decision-making processes, quality control and auditing improvement. Most quality-related issues are mainly the result of unacceptable auditing management process [13] as it depends on specific aspects in the auditing process and control procedures. [11].

Within the auditing process a choice of tools, techniques, methodologies and specific methods in the auditing team will follow. Some metrics from this factor are: the use of project management ultimate practices, field work review, planning, project scope, audit impact, auditing practice and procedures and the like. [4], [12].

\section{Human Factor}

Addresses the auditor or auditing professionals, client or the audited, management and key interactions of all involved in the process. It is important to consider quality perception through every participant-users, auditors, regulators and society- [25], since they have different views in regards of what constitutes and has an effect on the type of metrics used to assess the auditing quality.

The auditor or group of professionals in the audit, depending on the circumstance are responsible for the performance of an audit [13] and the result of their work will successfully reflect on a reliable audit report based on established standards. [17]. Given that experienced auditors follow standards well, are therefore associated to the unlikeliness of audit failure [26]. All these qualities lead to adequate planning and auditing programs generating reliable results which may directly affect client satisfaction, crucial when evaluating quality[6].

\section{Contextual Factor}

Related to external auditor elements and the auditing process, to include social and institutional force from both, the audited institution and the auditee, their regulatory environment and resource management.

Additionally, the environment in which auditing processes are carried out varies from one country to another. As a country develops and companies become larger, more security is particularly needed regarding internal processes as the environment turns more complex. As a consequence, laws, security requirements and corporate government processes, the estate of the laws and auditing inspections or when research fails the process and adoption of disciplinary measures become more effective if they are fulfilled apappropriately. [4] Thus, management and institution resource optimization should be considered upon strategy implementation so as to decrease costs for both, the auditee and the audited company [27]. Altogether, these contextual factors have the potential to affect directly or indirectly the nature of the auditing since they have significative interactive effects on the entries and auditing process [4].

In addition to perform the factorial analysis and to evaluate resulting factors, the impact each factor had on the auditing quality results was assessed and scores are calculated for each factor based on the corresponding metrics average. Table 7 shows each factor mean, variance and the number of metrics pertaining to each factor.

Table 7. Statistics per factor.

\begin{tabular}{cccc}
\hline Factor & Mean & Variance & Elements \\
\hline 1. Technical & 193,08 & 2167,371 & 34 \\
2. Human & 127,97 & 940,014 & 23 \\
\hline
\end{tabular}




\begin{tabular}{llll}
\hline 3. Contextual & 39,58 & 91,235 & 7 \\
\hline
\end{tabular}

The three affecting quality factors from the auditing results, the technical factor is the most significative due to the number of metrics found in its factor load, which is superior compared to the other two factors. Regarding the dimension reduction process, the technical factor revealed minimum-reduction totaling 5 discarded metrics: M42- Auditing team has approval methods for completed tasks in the auditing process., M47- Auditing team achieves planned objectives, M61-Reports presentation is done under IT auditing policies, standards, manuals, guidelines and practice, M64-Auditing team is has ample knowledge of auditing evidence gathering techniques and M70-Auditng plan developed according to IT auditing policies, standards, manuals, guidelines and practice

On the other hand, in the human factor 17 metrics were eliminated: M1-the leader of the auditing team or individual possesses leadership qualities, M2.-The representative for the organization which is being audited possesses leadership qualities, M3-Personnel who performs the auditing process has ample auditing experience, M4-Auditing team members demonstrate honesty and respect while doing their job, M5-Auditing team members work on the auditing ethically and transparently, M6- Auditing team keeps a cordial and respectful relationship with the auditee both verbally and in writing, M7- Auditing team fulfills client requirements, M8-Audtior knows how to listen and is receptive to the client, M13-Personnel performing the auditing has the ability to deal with sensitive situations, M14- Personnel performing the auditing demonstrates assertiveness in problem solving and demanding situations, M18-Auditor respects client confidentiality and information M23-Auditor reports to the person in charge events that may affect his independence, M25-Auditing team displays objectivity and integrity, M26-Auditng team executes the auditing impartially, without prejudice, M3- Auditor is skeptic during the auditory process, M32-Auditing team's expertise adds value to the auditee,M37-Auditing team holds regular formal and intelligible meetings for analysis progress and results.

As per contextual factor, 8 metrics: M80-An institution organizational structure is reflected in the auditing plan, M85-Auditor team present recommendations to the organization regarding international standards, local regulation, strategic objective updates as well as changes in the auditing environment, M87-Auditing team has all the required permits to develop the auditing process, M89-Auditing team is prepared to the risk of litigation, M90-Auditing team has access to human and technical resources for specialized audits, M91-Auditing team has access to required resources to comply with the scope and auditing calendar, M93-Auditing team is well aware of internal controls and M94-Auditing team identify client internal control system key elements, resulting in IT auditing quality-result evaluation tool comprised by 64 metrics.

\section{Conclusions}

At present, IT auditing is one of the fields taken very seriously, unfortunately there are not enough process authenticators, resulting in quality deficient audits caused by several internal and external factors.

Likewise, it can be concluded that IT auditing processes lack quality owing to deficiencies within the auditing process as well as management performed by incompetent auditors attributable to the absence of technology training and the use of data advanced techniques. Despite that auditing firms make great efforts to train their personnel it is possible to realize that only a few auditors are able to take on new challenges.

In this study, quality-affecting factors were pinned down, analyzed and compared to existent theoretical foundation, same that were categorized by technical, human and contextual factors. 
Based on the study performed, two factors were ruled-out that, according to the analysis have no significance in the IT auditing process exhibiting a deficiency of higher than 0,6 factorial loads, making the technical factor the most significative in IT auditing processes as it was the factor reveling less dimensions reduction plus a factorial load superior to human and contextual factors.

To conclude, it can be determined that by applying technical, human and contextual factors and resulting significant metrics there is an improvement in the IT auditing quality assessment process.

\section{Patents}

Author Contributions: For research articles with several authors, a short paragraph specifying their individual contributions must be provided. The following statements should be used "Conceptualization, D.I. and L.S.; methodology, D.I. and L.S.; formal analysis, D.I. and L.S.; investigation, D.I. and L.S.; resources, J.D. and T.S.; data curation M.O.; writing-original draft preparation, S.A.; writing-review and editing, D.I., L.S.; visualization, J.D. and M.O.; supervision, D.I.; project administration, D.I.; All authors have read and agreed to the published version of the manuscript." Please turn to the CRediT taxonomy for the term explanation. Authorship must be limited to those who have contributed substantially to the work reported.

Funding: This research received no external funding

Data Availability Statement: Not applicable.

Acknowledgments: The support provided by the Universidad Técnica del Norte to the Internal Auditors of Ecuador is appreciated.

Institutional Review Board Statement: Not applicable.

Informed Consent Statement: Not applicable.

Conflicts of Interest: The authors declare no conflict of interest

Author Contributions: Conceptualization, D.I. and L.S.; methodology, D.I. and L.S.; writing - original draft preparation, D.I. and L.S.; writing - review and editing, E.T. and E.G. All authors shared the authorship of the paper sections and All authors have read and agreed to the published version of the manuscript.

\section{Appendix A}

\section{IT Auditing Quality metrics}

\begin{tabular}{|c|c|c|}
\hline Code & Metric & Source \\
\hline M1 & $\begin{array}{l}\text { Auditing team leader or indiviual possesses } \\
\text { leadership skills }\end{array}$ & {$[10],[28]$} \\
\hline M2 & $\begin{array}{l}\text { The (auditee)organization's represtentitive } \\
\text { possesses leadership skills }\end{array}$ & [10], [28] \\
\hline M3 & $\begin{array}{l}\text { Personnel peforming the audit has ample auditor } \\
\text { experience. }\end{array}$ & $\begin{array}{l}{[1],[3],[4],[11],[12],} \\
{[14],[15],[17],[26]}\end{array}$ \\
\hline M4 & $\begin{array}{l}\text { Auditing team members demonstrate honesty and } \\
\text { respect when doing their job. }\end{array}$ & {$[4],[10],[17]$} \\
\hline M5 & $\begin{array}{l}\text { Members of the auditing team peroform ther audit } \\
\text { ethically and transparently. }\end{array}$ & {$[4],[10],[17]$} \\
\hline M6 & $\begin{array}{l}\text { Auditor team keeps a cordial and verbal and written } \\
\text { respectful relationship with the auditee }\end{array}$ & {$[1],[11],[12]$} \\
\hline M7 & Auditing team fulfills client requirements & {$[1],[11],[12]$} \\
\hline M8 & $\begin{array}{l}\text { Audtior knows how to listen and is receptive to the } \\
\text { client }\end{array}$ & {$[1],[11],[12]$} \\
\hline
\end{tabular}


M9

M10

M11

M12

M13

M14

M14

M15

M16

M17

M18

M19

M20

M21

M22

M23

M24

M25

M26

M27

M28

M29

M30

M31

M32

M33

M34
Auditing team makes sure the client takes part in the entire auditing process

[1], [11], [12]

Auditing team has client approval of the tasks developed

[1], [11], [12]

Auditing team and client direct efforts to a common goal

[1], [11], [12]

Personnel performing the audit the requiered competene to perform their job

$[5],[10],[12],[17]$,

[28]

$[5],[10],[12],[17]$,

[28] sinsitive situations

$[5],[10],[12],[17]$, [28]

Auditor possesses soft skills -personal characteristics and competencies that demonstrate the auditor gets along with others-

$[5],[10],[12],[17]$, [28]

[5], [10], [12], [17], [28]

[5], [10], [12], [17], [28]

Autditor respects client information and confidentiallity

[4], [10]

Auditor keeps an open mind when new ideas are suggested

[4], [10]

[4], [10]

Auditing team continues being independent in appereance and action

[1], [28], [29]

Auditing team does not get involved in activies that compromise their independence

[1], [28], [29]

Auditor reports to the person in charge events that may affect his independence

[1], [28], [29]

[13], [17], [29]

[13], [17], [29]

Auditin team demonstrates objectivity and integrity

Auditing team executes the audit impartially and with no prejudice

[13], [17], [29]

[30] to perform the audit

The auditor is concerned for his training and continuing training

Auditor has national and international certifications in the auditing and IT auditing field

Auditor exhibits skepticism during the entire auditing process

Auditing team expertise add value to the auditee the organization -

Members of auditing team demonstrate

[4], [5]

[1], [4], [15] conficedence regarding information security and data processing

Clients disputes are dealt with appropriately and objectively
[1], [4], [15]

[4], [12] 
M35

M36

M37

M38

M39

M40

M41

M42

M43

M44

M45

M46

M47

M48

M49

M50

M51

M52

M53

M54

M55 Risk evaluating model is comprehensive

M56 Auditing plan takes into account client-related risks

M57

M58

M59 inquiries

Those involved in the audit keep frequent communication

Auditing team hold regular formal intellible meetins for analyses progress and results

Auditor link up with experts as asupport in the auditing process to obtian client recommendations and results

Auditing team appropriately selects consultants and experts

Auditor follows policies and procedurtes that regulate ethical and professional compliance Auditing team uses templates and forms to document the process

Auditing team has approval procedures for completed auditing tasks

Auditor and those responsible for the organization auditee- follow up on auditing previous IT audiging issues

Audit findings and conclusions are an exact reflexion of the audited process real facts documented by auditing gathered evidence

Members of the auditing team and those responsible for the institution protect at all times information used in the process

Auditing team achieves objectives planned in the auditing

Findings, conclusions and recomemendations were positively approved by the client

Auditing assigned resources go accordingly to audit relevance and complexity

System, process and audited subject is important to the organization

Client understands the process and purpose of the IT auditing

In the scope, all required elements for a successful audit are addressed

Audit execution complies with the elements agreed in the scope completion deadline

Auditing process is developed accurately
Auditing team is available to attend to clients

[4], [12]

[4], [12]

[27], [31]

[10], [28]

[13], [29]

[13], [29]

[13], [29]

[13], [29]

[13], [29]

[1], [13], [18]

[1], [13], [18]

[5], [11], [12]

[5], [11], [12]

[3], [4], [12]

[4]

[4], [10], [11], [13] 
Scope, findings and recommendations are undertendable for anyone that makes use of the [4], [10], [11], [13] audit report

Reports presentation is done under

M61 policies,standars, manuals, practice and IT [4], [10], [11], [13] guidelines

M62 Auditing team performs fieldwork adequately

$[1],[4],[18]$

M63 Auditing is executed under IT auditing policies, standards, manuals, guidelines and practice

$[1],[4],[18]$

Auditing team is has ample knowledge of auditing evidence gathering techniques

$[1],[4],[18]$

M64

All tasks are developed according to planned

$[1],[4],[18]$

M65

Verification lists are completed, aproved and

M66 documented

M67 Workfield is checked by an expert

$[1],[4],[18]$

M68 Clilent or those responsible for the organization provide data gathering support

$[1],[4],[18]$

[1], [18]

Information and results from previous audits are available for revision

[1], [18]

Auditing plan is developed according to IT auditing policies, standards, manuals, guidelines and practice

$[1],[18]$ Objectives and auditing scope are appropriately specified

[1], [18]

[1], [18]

M72 Auditing tasks and tools are clerly described

M73

Auditing team memebers have a clear and coherent undestanding of the auditing plan

[1], [18]

M74 Budget and audit schedule are set up adequately

[1], [18]

M75 Required resources to perform the auditing are evaluated

[1], [18]

Personnel and equipment required assigend by the auditing are evaluated

[1], [18]

Auditing plan is addressed, made, checkedand

M77 approved by supervisors and those responsible for

[1], [18] the organization and auditing team members

M78

Auditing team uses IT auditing metodology to plan, manage and develop audits

[1], [12]

Auditig team uses technological tools and updated methodologies to perform their job

[1], [12]

An institution organizational structure is reflected

M80 on the auditing plan

[1], [4], [10], [12],

[18]

M81 Auditor promotes through his an organizational culture based on IT security good practice

[1], [4], [10], [12],

[18]

M82 Auditing team follows strict quality procedures

$[4],[5],[11]$

The auditing team leadaer is commited to quality control systems

$[4],[5],[11]$

Norms and regulations issued by control organisms are reflected on auditing plans

[4], [12]

Auditing team presents recommendations that the

M85 organization should follow because of

$[4],[12]$ international standard updates, local regulation, 


\begin{tabular}{|c|c|c|}
\hline & $\begin{array}{l}\text { strategic objectives and change in the auditing } \\
\text { enviroment }\end{array}$ & \\
\hline M86 & $\begin{array}{l}\text { Auditing team is knowledgeable in terms of } \\
\text { relevant information of the laws and regulations that } \\
\text { may have a significant impact on audit objectives }\end{array}$ & {$[4],[12]$} \\
\hline M87 & $\begin{array}{l}\text { Auditing team has the required permits to develop } \\
\text { and auditing process }\end{array}$ & {$[4],[12]$} \\
\hline M88 & $\begin{array}{l}\text { Disciplinary measures are applied in case of } \\
\text { auditing plan or current regulatory legal standards } \\
\text { non-compliance }\end{array}$ & {$[4],[12]$} \\
\hline M89 & $\begin{array}{l}\text { Auditing team es fully prepared before the risk of } \\
\text { litigation }\end{array}$ & {$[4],[28]$} \\
\hline M90 & $\begin{array}{l}\text { Auditing team has acces to technical and human } \\
\text { resources for an specialized audit }\end{array}$ & {$[18]$} \\
\hline M91 & $\begin{array}{l}\text { Auditing team has access to required resources to } \\
\text { comply with the scope and auditing calendar }\end{array}$ & {$[18]$} \\
\hline M92 & $\begin{array}{l}\text { Audit cost commesurate with tasks developed } \\
\text { and complexity }\end{array}$ & [11], [15], [28] \\
\hline M93 & Auditing team is well aware of internal controls & {$[28]$} \\
\hline M94 & $\begin{array}{l}\text { Auditing team identify client internal control system } \\
\text { key elements }\end{array}$ & {$[28]$} \\
\hline
\end{tabular}

\section{References}

1. D. Stoel, D. Havelka, and J. W. Merhout, "An analysis of attributes that impact information technology audit quality: A study of IT and financial audit practitioners," Int. J. Account. Inf. Syst., vol. 13, no. 1, pp. 60-79, 2012.

2. R. Bojorque and F. Pesántez-Avilés, "Academic Quality Management System Audit Using Artificial Intelligence Techniques," Adv. Intell. Syst. Comput., vol. 965, no. 28, pp. 275-283, 2020.

3. D. Dickins, A. J. Johnson-Snyder, and J. T. Reisch, "Selecting an auditor for Bradco using indicators of audit quality," J. Account. Educ., vol. 45, pp. 32-44, 2018.

4. International Auditing and Assurance Standards Board, A framework for audit quality. New York: International Federation of Accountants, 2014.

5. N. A. Sulaiman, S. Shahimi, and K. Nashtar, "People and Audit Process Attributes of Audit Quality: Evidence From Malaysia," Manag. Account. Rev., vol. 18, no. 2, p. 47, 2019.

6. R. Yuniarti and W. M. Zumara, "Audit Quality Attributes and Audit Client Satisfaction,” Int. J. Humanit. Manag. Sci., vol. 1, no. 1, pp. 96-100, 2013.

7. W. Knechel and A. Vanstraelen, "The relationship between auditor tenure and audit quality implied by going concern opinions," Auditing, vol. 26, no. 1, pp. 113-131, 2007.

8. D. Havelka and J. W. Merhout, "Internal information technology audit process quality: Theory development using structured group processes," Int. J. Account. Inf. Syst., vol. 14, no. 3, pp. 165-192, 2013.

9. D. E. Imbaquingo Esparza, M. B. Ron Egas, F. A. Cajas Sinchiguano, and R. A. Luje Misacango, “Evaluation model of computer audit methodologies based on inherent risk," Iber. Conf. Inf. Syst. Technol. Cist., pp. 24-27, 2020.

10. C. Holm and M. Zaman, "Regulating audit quality: Restoring trust and legitimacy," Account. Forum, vol. 36, no. 1, pp. 51-61, 2012.

11. W. Knechel, G. Krishnan, M. Pevzner, L. Shefchik, and U. Velury, “Audit quality: Insights from the academic literature," Auditing, vol. 32, no. 1, pp. 385-421, 2013.

12. D. Havelka and J. W. Merhout, “Development of an information technology audit process quality framework," Assoc. Inf. Syst. - AMCIS 2007 Proc., no. 61, pp. 910-916, 2007.

13. Committee Contact of Heads of EU SAIs, “Guidelines on Audit Quality,” p. 57, 2004.

14. F. Yasin and S. Nelson, “Audit Committee and Internal Audit: implications on audit quality," Int. J. Econ. Manag. Account., vol. 20, no. 2, pp. 8-10, 2012.

15. M. K. Harris and L. T. Williams, "Audit quality indicators: Perspectives from Non-Big Four audit firms and small company audit committees," Adv. Account., vol. 50, p. 100485, 2020.

16. A. Eilifsen, W. Knechel, and P. Wallage, "Application of the business risk audit model: A field study," Account. Horizons, vol. 15, no. 3, pp. 193-207, 2001.

17. S. Zahmatkesh and J. Rezazadeh, "The effect of auditor features on audit quality," Tékhne, vol. 15, no. 2, pp. 79-87, 2017. 
18. Y. Hasas Yeghaneh, M. Zangiabadi, and S. M. Dehghani Firozabadi, “Factors Affecting Information Technology Audit Quality," J. Invest. Manag., vol. 4, no. 5, pp. 196-203, 2015.

19. J. Ferrando and C. Anguiano, “El análisis factorial como técnica de investigación en psicología," Papeles del Psicólogo, vol. 31, no. 1, pp. 18-33, 2010.

20. L. Guti, “Cómo realizar e interpretar un análisis factorial exploratorio utilizando SPSS.,” REIRE Rev. d Innovació i Recer. en Educ., vol. 12 (2), pp. 1-14, 2019.

21. S. Lloret-Segura, A. Ferreres-Traver, A. Hernández-Baeza, and I. Tomás-Marco, “El Análisis Factorial Exploratorio de los Ítems: una guía práctica, revisada y actualizada," An. Psicol., vol. 30, no. 3, pp. 1151-1169, 2014.

22. J. Carcello, R. Hermanson, and N. McGrath, "Audit quality attributes: the perceptions of audit partners, preparers, and financial statement users," Audit. A J. Pract. Theory, vol. 11, pp. 1-15, 1992.

23. D. Imbaquingo, L. San Pedro, J. Díaz, T. Saltos, and S. Arciniega, “Let's talk about Computer Audit Quality. A systematic literature review," IEEE Xplore, In press.

24. S. de la Fuente, "Análisis Factorial," Madrid, 2011.

25. N. A. Sulaiman, F. M. Yasin, and R. Muhamad, “Perspectives on Audit Quality: an analysis,” Asian J. Account. Perspect., vol. 11, no. 1, pp. 1-27, 2018.

26. K. Ye, Y. Cheng, and J. Gao, "How individual auditor characteristics impact the likelihood of audit failure: Evidence from China," Adv. Account., vol. 30, no. 2, pp. 394-401, 2014.

27. E. Guindel, Calidad y seguridad de la información y auditoría informática. Leganés: Universidad Carlos III de Madrid, 2010.

28. Public Company Accounting Oversight Board, “Concept Release on Audit Quality Indicators," PCAOB, no. 005, pp. 1-61, 2015.

29. L. Strous, "Audit of information systems: The need for cooperation," Lect. Notes Comput. Sci. (including Subser. Lect. Notes Artif. Intell. Lect. Notes Bioinformatics), vol. 1521, pp. 264-274, 2002.

30. T. Xiao, C. Geng, and C. Yuan, "How audit effort affects audit quality: An audit process and audit output perspective," China J. Account. Res., vol. 13, no. 1, pp. 109-127, Mar. 2020.

31. R. Refaat and I. M. El-Henawy, “Innovative method to evaluate quality management system audit results' using single value neutrosophic number," Cogn. Syst. Res., vol. 57, pp. 197-206, 2019. 